\title{
Pengaruh Pelebaran Ruas Jalan terhadap Perubahan Kapasitas Jalan dan Lingkungan
}

\author{
Nirwana Puspasari \\ Program Studi Teknik Sipil Universitas Muhammadiyah Palangkaraya
}

\begin{abstract}
ABSTRAK. Meningkatnya volume lalu lintas di ruas jalan primer perkotaan Palangka Raya seiring berjalannya waktu menuntut adanya peningkatan kapasitas ruas jalan tersebut. Pelebaran ke arah sisi jalan cukup mahal karena harus membebaskan lahan yang sudah berdiri bangunan di sisi jalan tersebut, seperti adanya saluran drainase yang harus digeser bahkan menebang pohon penghijauan di sisi jalan tersebut. Untuk itu maka pelebaran dibuat ke arah as jalan secara bervariasi yaitu 0,5 meter, 1 meter dan 1,5 meter, yang secara otomatis berarti mengurangi lebar median jalan yang juga sebagai media tanaman. Ruas jalan yang dianalisa adalah jalan Diponegoro, RTA. Milono, Imam Bonjol, Yos Soedarso dan G. Obos. Metode penelitian yang di gunakan adalah metode kuantitatif dengan cara survey lapangan. Data yang diambil adalah data tipe jalan, geometrik jalan, tipe lingkungan, hambatan samping dan jumlah penduduk yang mempengaruhi kapasitas jalan kota, serta data jenis tanaman yang ada di median jalan tersebut. Yang dianalisis adalah kecepatan arus bebas dan kapasitas jalan seiring penambahan lebar jalan 0,5 m, 1,0 m dan 1,5 m. Hasil analisa data menunjukan kecepatan arus bebas pada ruas jalan kota tersebut berkisar 50,41 km/jam sampai dengan 55,43\%.km/jam untuk ruas $A$, dan 48,01 km/jam sampai dengan 54,67 $\mathrm{km} / \mathrm{jam}$ untuk ruas $\mathrm{B}$, menunjukan kondisi arus lalu lintas masih berjalan dengan lancar. Pelebaran ruas jalan A meningkatkan kapasitas jalan tersebut berkisar 2,8603\% sampai dengan 3,9139\% untuk pelebaran 0,5 meter, berkisar 5,6145\% sampai dengan $7,8278 \%$ untuk pelebaran 1,0 meter dan berkisar $8,4746 \%$ sampai dengan 31,9542.\% untuk pelebaran 1,5 meter. Pelebaran ruas jalan B meningkatkan kapasitas jalan tersebut berkisar 2,7458\% sampai $10,8399 \%$ untuk pelebaran 0,5 meter, berkisar 5,7296\% sampai dengan $14,3666 \%$ untuk pelebaran 1,0 meter dan berkisar $8,6486 \%$ sampai dengan $40,413 \%$ untuk pelebaran 1,5 meter. Pohon yang dominan di tanam pada median jalan adalah pohon tanjung dengan kemampuan menyerap karbon monoksida sebesar $35,94 \mathrm{mg} / \mathrm{m}^{2}$. Dengan berkurangnya lebar median selebar 0,5m, $1 \mathrm{~m}$ dan 1,5 m dari masing-masing ruas A dan B, maka maka terjadi pengurangan penyerapan karbon monoksida sebesar 35,94 mg, 71,88 mg dan 107,82 mg untuk setiap panjang 1 meter ruas jalan.
\end{abstract}

Kata Kunci: Sampel, Model, Bangkitan Perjalanan

\section{PENDAHULUAN}

Palangka Raya merupakan Ibu Kota Provinsi Kalimantan Tengah, merupakan wilayah yang sangat luas bagi sebuah kota dengan luas wilayah $2400 \mathrm{~km}^{2}$. Pola penyebaran penduduk dan kegiatan sosial ekonomi masyarakat seperti daerah pemukiman, pertokoan, sekolah, kegiatan 
sosial dan perkantoran tersebar secara luas, sehingga untuk memenuhi semua kebutuhan tersebut setiap orang memerlukan sarana dan prasarana transportasi untuk bertransportasi.

Pertumbuhan jumlah penduduk mengakibatkan perkembangan dan pergerakan perjalanan di Kota Palangka Raya. Pertumbuhan yang seimbang antara sarana dan prasarana transportasi disertai kepedulian akan lingkungan diharapkan mampu mengatasi permasalahan transportasi dimasa yang akan datang seperti kemacetan lalu lintas dan permasalahan lingkungan seperti volume udara, suara dan air tanah.

Seiring bertambahnya volume lalu lintas di ruas jalan primer perkotaan menuntut adanya peningkatan kapasitas ruas jalan tersebut dengan melakukan pelebaran ruas jalan. Pelebaran yang dilakukan pada umumnya ke arah dua sisi jalan. Akan tetapi jika pelebaran ke arah sisi jalan sudah tidak memungkinkan untuk dilakukan karena adanya pohon penghijauan jalan juga drainase, maka pelebaran akan dilakukan kearah tengah jalan dengan mengurangi lebar median. Dengan berkurangnya lebar median, maka secara otomatis mengurangi area hijau yang ada di median tersebut. . Padahal kita tahu bahwa selain memperindah dan mempercantik kota, tanaman tersebut juga membantu menyerap karbon monoksida yang dihasilkan dari pembakaran knalpot kendaraan bermotor. Jika hal tersebut diabaikan, polusi udara akan meningkat seiring dengan bertambahnya volume kendaraan bermotor.

\section{TUJUAN PENELITIAN}

Tujuan dari penelitian ini adalah untuk mengetahui pengaruh perubahan kapasitas ruas jalan utama di Kota Palangka Raya terkait pengurangan median jalan sebagai media minimalisasi pencemaran udara.

\section{TINJAUAN PUSTAKA}

Faktor-faktor yang mempengaruhi hambatan samping, kecepatan arus bebas, dan kapasitas adalah sebagai berikut:

\section{Hambatan Samping}

\section{Faktor Bobot Hambatan Samping}

a. Pejalan kaki $\left(\mathrm{F}_{\mathrm{Ped}}\right)$

b. Kendaraan keluar masuk sisi jalan $\left(\mathrm{F}_{\mathrm{EEV}}\right)$

c. Kendaraan bergerak lambat $\left(\mathrm{F}_{\mathrm{SMV}}\right)$

d. Kendaraan berhenti $\left(\mathrm{F}_{\mathrm{SV}}\right)$

Tabel 1. Faktor Hambatan Samping

\begin{tabular}{clc}
\hline No. & \multicolumn{1}{c}{ Hambatan Samping } & Faktor \\
\hline 1 & Pejalan kaki & 0,5 \\
2 & Kendaraan keluar masuk sisi jalan & 0,7 \\
3 & Kendaraan bergerak lambat & 0,4 \\
4 & Kendaraan parkir/berhenti & 1,0 \\
\hline
\end{tabular}

\section{Kelas Hambatan Samping}

Tabel 2. Kelas Hambatan Samping

\begin{tabular}{lccl}
\hline $\begin{array}{c}\text { Kelas } \\
\text { Hambatan } \\
\begin{array}{c}\text { Samping } \\
\text { (SFC) }\end{array}\end{array}$ & Kode & $\begin{array}{c}\text { Jumlah berbobot } \\
\text { kejadian per 200 } \\
\text { m per jam } \\
\text { (dua sisi) }\end{array}$ & Kondisi khusus \\
\hline $\begin{array}{l}\text { Sangat } \\
\text { rendah }\end{array}$ & VL & $<100$ & $\begin{array}{l}\text { Daerah } \\
\text { pemukiman; jalan } \\
\text { Dengan jalan } \\
\text { samping }\end{array}$ \\
\hline Rendah & L & $100-299$ & $\begin{array}{l}\text { Daerah } \\
\text { pemukiman, } \\
\text { beberapa } \\
\text { kendaraan umum }\end{array}$ \\
\hline Sedang & M & $300-499$ & $\begin{array}{l}\text { Daerah industri; } \\
\text { beberapa toko di } \\
\text { sisi jalan }\end{array}$ \\
& & & $\begin{array}{l}\text { Daerah komersial; } \\
\text { aktifitas sisi jalan } \\
\text { tinggi }\end{array}$ \\
\hline Tinggi & H & $500-899$ & $\begin{array}{l}\text { Daerah komersial } \\
\text { dengan aktifitas } \\
\text { pasar di samping } \\
\text { jalan }\end{array}$ \\
\hline Sangat & VH & $>900$ & \\
Tinggi & & & \\
& & & \\
\hline
\end{tabular}

Faktor Berbobot :

$$
\mathrm{FB}=\left(\mathrm{Ped} \times \mathrm{F}_{\mathrm{Ped}}\right)+\left(\mathrm{EEV} \times \mathrm{F}_{\mathrm{EEV}}\right)+
$$$$
\left(\mathrm{SMV} \times \mathrm{F}_{\mathrm{SMV}}\right)+\left(\mathrm{SV} \times \mathrm{F}_{\mathrm{SV}}\right)
$$

\section{Kecepatan Arus Bebas}

1. Kecepatan Arus Bebas Dasar (FVo)

Tabel 3. Kecepatan Arus Bebas

\begin{tabular}{|c|c|c|c|c|}
\hline \multirow[b]{2}{*}{ Tipe Jalan } & \multicolumn{4}{|c|}{ Kecepatan Arus Bebas } \\
\hline & $\mathbf{L V}$ & $\mathrm{HV}$ & MC & $\begin{array}{c}\text { Semua } \\
\text { kendaraan } \\
\text { (rata-rata) }\end{array}$ \\
\hline $\begin{array}{l}\text { Enam-lajur terbagi } \\
(6 / 2 \mathrm{D}) \text { atau } \\
\text { Tiga-lajur satu-arah }(3 / 1)\end{array}$ & 61 & 52 & 48 & 57 \\
\hline $\begin{array}{l}\text { Empat-lajur terbagi (4/2 } \\
\text { D) atau } \\
\text { Dua-lajur satu-arah }(2 / 1)\end{array}$ & 57 & 50 & 47 & 55 \\
\hline $\begin{array}{l}\text { Empat-lajur tak-terbagi } \\
\text { (4/2 UD) }\end{array}$ & 53 & 46 & 43 & 51 \\
\hline $\begin{array}{l}\text { Dua-lajur tak-terbagi } \\
\text { (2/2 UD) }\end{array}$ & 44 & 40 & 40 & 42 \\
\hline
\end{tabular}




\section{Penyesuaian Kecepatan Arus Bebas} Untuk Lebar Jalur Lalu Lintas $\left(\mathbf{F V}_{\mathbf{W}}\right)$

Tabel 4. Faktor Lebar Jalur lalu Lintas

\begin{tabular}{|c|c|c|}
\hline Tipe Jalan & $\begin{array}{c}\begin{array}{c}\text { Lebar jalur lalu lintas } \\
\text { efektif }\left(\mathbf{W}_{\mathrm{C}}\right) \text { (meter) }\end{array} \\
\end{array}$ & $\begin{array}{c}F_{\mathbf{W}} \\
(\mathbf{k m} / \mathbf{j a m})\end{array}$ \\
\hline \multirow{5}{*}{$\begin{array}{l}\text { Empat lajur terbagi } \\
\text { atau } \\
\text { Jalan satu arah }\end{array}$} & Per lajur: 3,00 & -4 \\
\hline & 3,25 & -2 \\
\hline & 3,50 & 0 \\
\hline & 3,75 & 2 \\
\hline & 4,00 & 4 \\
\hline \multirow{5}{*}{$\begin{array}{l}\text { Empat lajur tak } \\
\text { terbagi }\end{array}$} & Per lajur: 3,00 & -4 \\
\hline & 3,25 & -2 \\
\hline & 3,50 & 0 \\
\hline & 3,75 & 2 \\
\hline & 4,00 & 4 \\
\hline \multirow[t]{7}{*}{ Dua lajur tak terbagi } & Total : & $-9,5$ \\
\hline & 6 & -3 \\
\hline & 7 & 0 \\
\hline & 8 & 3 \\
\hline & 9 & 4 \\
\hline & 10 & 6 \\
\hline & 11 & 7 \\
\hline
\end{tabular}

3. Faktor Penyesuaian Kecepatan Arus Bebas Untuk Hambatan Samping $\left(\right.$ FFV $\left._{\text {SF }}\right)$

a. Jalan Dengan Bahu

Tabel 5. Faktor Hambatan Samping (Bahu)

\begin{tabular}{|c|c|c|c|c|c|}
\hline \multirow[t]{2}{*}{$\begin{array}{l}\text { Tipe } \\
\text { Jalan }\end{array}$} & \multirow{2}{*}{$\begin{array}{c}\text { Kelas } \\
\text { Hambatan } \\
\text { Samping } \\
\text { (SFC) }\end{array}$} & \multicolumn{4}{|c|}{$\begin{array}{l}\text { Faktor penyesuaian untuk hambatan } \\
\text { samping dan lebar bahu } \\
\text { Lebar bahu efektif rata-rata } W_{S}(m)\end{array}$} \\
\hline & & $\leq \mathbf{0 , 5}$ & 1,0 & 1,5 & $\geq 2$ \\
\hline \multirow{5}{*}{$\begin{array}{l}\text { Empat } \\
\text { lajur } \\
\text { terbagi } \\
4 / 2 \mathrm{D}\end{array}$} & $\begin{array}{l}\text { Sangat } \\
\text { rendah }\end{array}$ & 1,02 & 1,03 & 1,03 & 1,04 \\
\hline & Rendah & 0,98 & 1,00 & 1,02 & 1,03 \\
\hline & Sedang & 0,94 & 0,97 & 1,00 & 1,02 \\
\hline & Tinggi & 0,89 & 0,93 & 0,96 & 0,99 \\
\hline & $\begin{array}{l}\text { Sangat } \\
\text { Tinggi }\end{array}$ & 0,84 & 0,88 & 0,92 & 0,96 \\
\hline \multirow{5}{*}{$\begin{array}{c}\text { Empat } \\
\text { lajur tak } \\
\text { terbagi } \\
4 / 2 \text { UD }\end{array}$} & $\begin{array}{l}\text { Sangat } \\
\text { Rendah }\end{array}$ & 1,02 & 1,03 & 1,03 & 1,04 \\
\hline & Rendah & 0,98 & 1,00 & 1,02 & 1,03 \\
\hline & Sedang & 0,93 & 0,96 & 0,99 & 1,02 \\
\hline & Tinggi & 0,87 & 0,91 & 0,94 & 0,98 \\
\hline & $\begin{array}{l}\text { Sangat } \\
\text { Tinggi }\end{array}$ & 0,80 & 0,86 & 0,90 & 0,95 \\
\hline \multirow{4}{*}{$\begin{array}{c}\text { Dua lajur } \\
\text { tak } \\
\text { terbagi } \\
2 / 2 \mathrm{UD} \\
\text { atau }\end{array}$} & $\begin{array}{l}\text { Sangat } \\
\text { Rendah }\end{array}$ & 1,00 & 1,01 & 1,01 & 1,01 \\
\hline & Rendah & 0,96 & 0,98 & 0,99 & 1,00 \\
\hline & Sedang & 0,91 & 0,93 & 0,96 & 0,99 \\
\hline & Tinggi & 0,82 & 0,86 & 0,90 & 0,95 \\
\hline $\begin{array}{c}\text { Jalan satu } \\
\text { arah }\end{array}$ & $\begin{array}{l}\text { Sangat } \\
\text { Tinggi }\end{array}$ & 0,73 & 0,79 & 0,85 & 0,91 \\
\hline
\end{tabular}

b. Jalan Dengan Kerb

Tabel 6. Faktor Hambatan Samping

\begin{tabular}{|c|c|c|c|c|c|}
\hline \multirow[t]{2}{*}{$\begin{array}{c}\text { Tipe } \\
\text { Jalan }\end{array}$} & \multirow{2}{*}{$\begin{array}{c}\text { Kelas } \\
\text { Hambatan } \\
\text { Samping } \\
\text { (SFC) }\end{array}$} & \multicolumn{4}{|c|}{$\begin{array}{c}\text { Faktor penyesuaian untuk } \\
\text { hambatan samping dan lebar bahu } \\
\text { Lebar bahu efektif rata-rata } W_{S}(\mathrm{~m})\end{array}$} \\
\hline & & $\leq 0,5$ & 1,0 & 1,5 & $\geq 2$ \\
\hline \multirow{5}{*}{$\begin{array}{l}\text { Empat } \\
\text { lajur } \\
\text { terbagi } \\
4 / 2 \mathrm{D}\end{array}$} & $\begin{array}{l}\text { Sangat } \\
\text { rendah }\end{array}$ & 1,00 & 1,01 & 1,01 & 1,02 \\
\hline & Rendah & 0,97 & 0,98 & 0,99 & 1,00 \\
\hline & Sedang & 0,93 & 0,95 & 0,97 & 0,99 \\
\hline & Tinggi & 0,87 & 0,90 & 0,93 & 0,96 \\
\hline & $\begin{array}{l}\text { Sangat } \\
\text { Tinggi }\end{array}$ & 0,81 & 0,85 & 0,88 & 0,92 \\
\hline
\end{tabular}

Tabel 6. Lanjutan

\begin{tabular}{|c|c|c|c|c|c|}
\hline \multirow[t]{2}{*}{$\begin{array}{c}\text { Tipe } \\
\text { Jalan }\end{array}$} & \multirow{2}{*}{$\begin{array}{c}\text { Kelas } \\
\text { Hambatan } \\
\text { Samping } \\
\text { (SFC) }\end{array}$} & \multicolumn{4}{|c|}{$\begin{array}{c}\text { Faktor penyesuaian untuk } \\
\text { hambatan samping dan lebar bahu } \\
\text { Lebar bahu efektif rata-rata } W_{\mathrm{S}}(\mathrm{m})\end{array}$} \\
\hline & & $\leq 0,5$ & 1,0 & 1,5 & $\geq 2$ \\
\hline \multirow{5}{*}{$\begin{array}{c}\text { Empat } \\
\text { lajur tak } \\
\text { terbagi } \\
4 / 2 \text { UD }\end{array}$} & $\begin{array}{c}\text { Sangat } \\
\text { Rendah }\end{array}$ & 1,00 & 1,01 & 1,01 & 1,02 \\
\hline & Rendah & 0,96 & 0,98 & 0,99 & 1,00 \\
\hline & Sedang & 0,91 & 0,93 & 0,96 & 0,98 \\
\hline & Tinggi & 0,84 & 0,87 & 0,90 & 0,94 \\
\hline & $\begin{array}{l}\text { Sangat } \\
\text { Tinggi }\end{array}$ & 0,77 & 0,81 & 0,85 & 0,90 \\
\hline \multirow{4}{*}{$\begin{array}{c}\text { Dua lajur } \\
\text { tak } \\
\text { terbagi } \\
2 / 2 \mathrm{UD} \\
\text { atau }\end{array}$} & $\begin{array}{l}\text { Sangat } \\
\text { Rendah }\end{array}$ & 0,98 & 0,99 & 0,99 & 1,00 \\
\hline & Rendah & 0,93 & 0,95 & 0,96 & 0,98 \\
\hline & Sedang & 0,87 & 0,89 & 0,92 & 0,95 \\
\hline & Tinggi & 0,78 & 0,81 & 0,84 & 0,88 \\
\hline $\begin{array}{c}\text { Jalan satu } \\
\text { arah }\end{array}$ & $\begin{array}{l}\text { Sangat } \\
\text { Tinggi }\end{array}$ & 0,78 & 0,81 & 0,84 & 0,88 \\
\hline
\end{tabular}

4. Faktor Penyesuaian Kecepatan Arus Bebas Untuk Ukuran Kota $\left(\right.$ FFV $\left._{\mathbf{C S})}\right)$

Tabel 7. Faktor Ukuran Kota

\begin{tabular}{cc}
\hline $\begin{array}{c}\text { Ukuran Kota (jlh } \\
\text { penduduk) }\end{array}$ & $\begin{array}{c}\text { Faktor Penyesuaian } \\
\text { Untuk Ukuran Kota }\end{array}$ \\
\hline$<0,1$ & 0,90 \\
$0,1-0,5$ & 0,93 \\
$0,5-1,0$ & 0,95 \\
$1,0-3,0$ & 1,00 \\
$>3$ & 1,03 \\
\hline
\end{tabular}

Rumus Kecepatan Arus Bebas

$\mathbf{F V}=\left(\mathbf{F V}_{\mathbf{o}}+\mathbf{F V}_{\mathbf{w}}\right) \times \mathbf{F F V}_{\mathbf{S F}} \times \mathbf{F F V}_{\mathbf{C S}}$

Dimana :

$\mathrm{FV}=$ Kecepatan arus bebas kendaraan ringan $(\mathrm{km} / \mathrm{jam})$

$\mathrm{FV}_{\mathrm{o}}=$ Kecepatan arus bebas dasar kendaraan ringan $(\mathrm{km} / \mathrm{jam})$

$\mathrm{FV}_{\mathrm{w}}=$ Penyesuaian lebar jalur lalu lintas $(\mathrm{km} / \mathrm{jam})$

$\mathrm{FFV}_{\mathrm{SF}}=$ Faktor penyesuaian hambatan samping

$\mathrm{FFV}_{\mathrm{CS}}=$ Faktor penyesuaian ukuran kota

$$
\begin{aligned}
& \text { Analisis Kapasitas }(C) \\
& \mathrm{C}=\mathrm{C}_{\mathrm{o}} \times \mathrm{FC}_{\mathrm{W}} \times \mathrm{FC}_{\mathrm{SP}} \times \mathrm{FC}_{\mathrm{SF}} \times \mathrm{FC}_{\mathrm{CS}}
\end{aligned}
$$

\section{Dimana :}

C = Kapasitas (smp/jam)

$\mathrm{C}_{\mathrm{o}} \quad=$ Kapasitas dasar (smp/jam)

$\mathrm{FC}_{\mathrm{W}}=$ Faktor penyesusaian lebar jalur lalu lintas

$\mathrm{FC}_{\mathrm{SP}}=$ Faktor penyesuaian pemisah arah

$\mathrm{FC}_{\mathrm{SF}}=$ Faktor penyesuaian hambatan samping

$\mathrm{FC}_{\mathrm{CS}}=$ Faktor penyesuaian ukuran kota 


\section{Faktor Kapasitas Dasar Jalan Perkotaan}

Tabel 8. Kapasitas Dasar

\begin{tabular}{lcc}
\hline \multicolumn{1}{c}{ Tipe Jalan } & $\begin{array}{c}\text { Kapasitas Dasar } \\
\text { (smp/jam) }\end{array}$ & Catatan \\
\hline $\begin{array}{l}\text { Empat-lajur terbagi } \\
\text { atau jalan satu arah }\end{array}$ & 1650 & Per lajur \\
$\begin{array}{l}\text { Empat-lajur tak- } \\
\text { terbagi }\end{array}$ & 1500 & Per lajur \\
$\begin{array}{l}\text { Dua-lajur tak- } \\
\text { terbagi }\end{array}$ & 2900 & $\begin{array}{c}\text { Total dua } \\
\text { arah }\end{array}$ \\
\hline
\end{tabular}

2. Faktor Penyesuaian Kapasitas Untuk Lebar Jalur Lalu Lintas $\left(\mathbf{F C}_{\mathbf{W}}\right)$

Tabel 9. Faktor Lebar Jalur

\begin{tabular}{lcc}
\hline \multicolumn{1}{c}{ Tipe Jalan } & $\begin{array}{c}\text { Lebar jalur lalu } \\
\text { lintas efektif } \\
\text { (Wc) meter }\end{array}$ & $\mathbf{F C}_{\mathbf{W}}$ \\
\hline Empat-lajur terbagi & Per lajur : & \\
atau jalan satu-arah & 3,00 & 0,92 \\
& 3,25 & 0,96 \\
& 3,50 & 1,00 \\
Empat-lajur tak- & 3,75 & 1,04 \\
terbagi & 4,00 & 1,08 \\
& Per lajur : & \\
& 3,00 & 0,91 \\
& 3,25 & 0,95 \\
Dua-lajur tak- & 3,50 & 1,00 \\
terbagi & 3,75 & 1,05 \\
& 4,00 & 1,09 \\
& Total dua arah & \\
& 5 & 0,56 \\
& 6 & 0,87 \\
& 7 & 1,00 \\
& 8 & 1,14 \\
& 9 & 1,25 \\
& 10 & 1,29 \\
& 11 & 1,34 \\
\hline
\end{tabular}

\section{Faktor Penyesuaian Kapasitas Untuk} Pemisahan Arah $\left(\right.$ FC $\left._{\text {SP }}\right)$

Tabel 10. Faktor Pemisah Arah

\begin{tabular}{|c|c|c|c|c|c|c|}
\hline \multicolumn{2}{|c|}{$\begin{array}{c}\text { Pemisah arah } \\
\text { SP \% \% } \%\end{array}$} & $\begin{array}{l}50- \\
50\end{array}$ & $\begin{array}{l}55- \\
45\end{array}$ & $\begin{array}{l}60- \\
40\end{array}$ & $\begin{array}{l}65- \\
35\end{array}$ & $\begin{array}{l}70- \\
30\end{array}$ \\
\hline \multirow{4}{*}{$\mathbf{F C}_{\mathrm{SP}}$} & Dua-lajur & 1,00 & 0,97 & 0,94 & 0,91 & 0,88 \\
\hline & $2 / 2$ & & & & & \\
\hline & Empat- & 1,00 & 0,98 & 0,97 & 0,95 & 0,94 \\
\hline & lajur $4 / 2$ & & 5 & & 5 & \\
\hline
\end{tabular}

\section{Faktor Penyesuaian Kapasitas Untuk} Hambatan Samping $\left(\mathrm{FC}_{\mathrm{SF}}\right)$

\section{a. Jalan dengan Bahu}

Tabel 11. Faktor Hambatan Samping (Bahu)

\begin{tabular}{cccccc}
\hline \multirow{2}{*}{$\begin{array}{c}\text { Tipe } \\
\text { Jalan }\end{array}$} & $\begin{array}{c}\text { Kelas } \\
\text { hambatan } \\
\text { samping }\end{array}$ & \multicolumn{3}{c}{$\begin{array}{c}\text { Faktor penyesuaian untuk hambatan } \\
\text { sampaing dan lebar bahu } \boldsymbol{F} \boldsymbol{C}_{\boldsymbol{S F}}\end{array}$} \\
\cline { 3 - 6 } & & \multicolumn{4}{c}{ Lebar bahu efektif $\boldsymbol{W}_{\boldsymbol{S}}$} \\
\cline { 3 - 6 } & $\mathbf{6 , \mathbf { 0 }}$ & $\mathbf{1 , 0}$ & $\mathbf{1 , 5}$ & $\geq \mathbf{2 , 0}$ \\
\hline $\mathbf{4 / 2} \mathbf{D}$ & $\mathbf{V L}$ & 0,96 & 0,98 & 1,01 & 1,03 \\
& $\mathbf{L}$ & 0,94 & 0,97 & 1,00 & 1,02 \\
& $\mathbf{M}$ & 0,92 & 0,95 & 0,98 & 1,00 \\
& $\mathbf{H}$ & 0,88 & 0,92 & 0,95 & 0,98 \\
& $\mathbf{V H}$ & 0,84 & 0,88 & 0,92 & 0,96 \\
\hline
\end{tabular}

Tabel 11. Lanjutan

\begin{tabular}{lccccc}
\hline \multirow{2}{*}{$\begin{array}{c}\text { Tipe } \\
\text { Jalan }\end{array}$} & $\begin{array}{c}\text { Kelas } \\
\text { hambatan } \\
\text { samping }\end{array}$ & \multicolumn{3}{c}{$\begin{array}{c}\text { Faktor penyesuaian untuk hambatan } \\
\text { sampaing dan lebar bahu } \boldsymbol{F} \boldsymbol{C}_{\boldsymbol{S F}}\end{array}$} \\
\cline { 3 - 6 } & & \multicolumn{4}{c}{ Lebar bahu efektif $\boldsymbol{W}_{\boldsymbol{S}}$} \\
\cline { 3 - 6 } 4/2 UD & $\mathbf{V L}$ & 0,96 & 0,99 & 1,01 & 1,03 \\
& $\mathbf{L}$ & 0,94 & 0,97 & 1,00 & 1,02 \\
& $\mathbf{M}$ & 0,92 & 0,95 & 0,98 & 1,00 \\
& $\mathbf{H}$ & 0,87 & 0,91 & 0,94 & 0,98 \\
& $\mathbf{V H}$ & 0,80 & 0,86 & 0,90 & 0,95 \\
2/2 UD & VL & 0,94 & 0,96 & 0,99 & 1,01 \\
atau & $\mathbf{L}$ & 0,92 & 0,94 & 0,97 & 1,00 \\
Jalan & $\mathbf{M}$ & 0,89 & 0,92 & 0,95 & 0,98 \\
satu & $\mathbf{H}$ & 0,82 & 0,86 & 0,90 & 0,95 \\
arah & VH & 0,73 & 0,79 & 0,85 & 0,91 \\
\hline
\end{tabular}

\section{b. Jalan dengan Kereb}

Tabel 12. Faktor Hambatan Samping (Kerb)

\begin{tabular}{|c|c|c|c|c|c|}
\hline \multirow{3}{*}{$\begin{array}{c}\text { Tipe } \\
\text { Jalan }\end{array}$} & \multirow{3}{*}{$\begin{array}{c}\text { Kelas } \\
\text { hambatan } \\
\text { samping }\end{array}$} & \multicolumn{4}{|c|}{$\begin{array}{c}\text { Faktor penyesuaian untuk } \\
\text { hambatan samping } \& \text { jarak kerb- } \\
\text { penghalang }\left(\mathrm{FC}_{\mathrm{SF}}\right)\end{array}$} \\
\hline & & \multicolumn{4}{|c|}{ Lebar bahu efektif $W_{S}$} \\
\hline & & $\leq 0,5$ & 1,0 & 1,5 & $\geq 2,0$ \\
\hline \multirow[t]{5}{*}{ 4/2 D } & VL & 0,95 & 0,97 & 0,99 & 1,01 \\
\hline & $\mathbf{L}$ & 0,94 & 0,96 & 0,98 & 1,00 \\
\hline & $\mathbf{M}$ & 0,91 & 0,93 & 0,95 & 0,98 \\
\hline & $\mathbf{H}$ & 0,86 & 0,89 & 0,92 & 0,95 \\
\hline & VH & 0,81 & 0,85 & 0,88 & 0,92 \\
\hline \multirow[t]{5}{*}{ 4/2 UD } & VL & 0,95 & 0,97 & 0,99 & 1,01 \\
\hline & $\mathbf{L}$ & 0,93 & 0,95 & 0,97 & 1,00 \\
\hline & $\mathbf{M}$ & 0,90 & 0,92 & 0,95 & 0,97 \\
\hline & $\mathbf{H}$ & 0,84 & 0,87 & 0,90 & 0,93 \\
\hline & VH & 0,77 & 0,81 & 0,85 & 0,90 \\
\hline 2/2 UD & VL & 0,93 & 0,95 & 0,97 & 0,99 \\
\hline atau & $\mathbf{L}$ & 0,90 & 0,92 & 0,95 & 0,97 \\
\hline Jalan & M & 0,86 & 0,88 & 0,91 & 0,94 \\
\hline satu & $\mathbf{H}$ & 0,78 & 0,81 & 0,84 & 0,88 \\
\hline arah & VH & 0,68 & 0,72 & 0,77 & 0,82 \\
\hline
\end{tabular}

\section{Faktor Penyesuaian Untuk Kapasitas} Ukuran Kota $\left(\mathrm{FC}_{\mathrm{CS}}\right)$

Tabel 13. Faktor Ukuran Kota

\begin{tabular}{cc}
\hline $\begin{array}{c}\text { Ukuran Kota (Juta } \\
\text { penduduk) }\end{array}$ & $\begin{array}{c}\text { Faktor penyesuaian } \\
\text { untuk ukurn kota }\end{array}$ \\
\hline$<0,1$ & 0,86 \\
$0,1-0,5$ & 0,90 \\
$0,5-1,0$ & 0,94 \\
$1,0-3,0$ & 1,00 \\
$>3,0$ & 1,04 \\
\hline
\end{tabular}

\section{Tumbuhan}

Pohon melakukan proses fotosintesis untuk membentuk zat makanan atau energi yang dibutuhkan untuk kehidupannya. Dalam kegiatan fotosintesis tersebut tumbuhan menyerap karbondioksida dan air yang kemudian diubah menjadi glukosa dan oksigen dengan bantuan cahaya. Daya serap karbondioksida sebuah pohon ditentukan oleh luas keseluruhan daun, umur daun, dan fase pertumbuhan tanaman. Selain itu, pohon-pohon yang berbunga dan berbuah memiliki kemampuan berfotosintesis yang lebih tinggi sehingga mampu sebagai 
penyerap karbondioksida yang lebih baik misalnya penanaman pohon tanjung.

\section{METODE PENELITIAN \\ Metode Penelitian}

Metode yang digunakan pada penelitian ini adalah metode kuantitatif.

\section{Teknik Pengumpulan Data}

\section{Data Primer}

Pengumpulan dilakukan dengan cara observasi lapangan, seperti :

a. Melakukan pengamatan dan pencacahan kendaraan bergerak lambat, kendaraan berhenti/parkir, kendaraan keluar masuk sisi jalan dan jumlah pejalan kaki yang berada di segmen jalan yang akan dianalisis.

b. Mengukur geometrik jalan seperti lebar jalan, lebar median, lebar trotoar, lebar bahu, dan jarak kereb ke penghalang.

\section{Data Sekunder}

Data sekunder diperoleh dari instansi yang berkaitan dengan penelitian ini seperti peta lokasi penelitian dan jumlah penduduk Kota Palangka Raya.

\section{Batasan masalah}

Ruas jalan yang dianalisis adalah jalanjalan primer yang mempunyai median jalan yang cukup lebar dan diberi tanaman hijau kota, diantaranya adalah Jalan Diponegoro, Jalan RTA. Milono, Jalan G. Obos, Jalan Imam Bonjol, Jalan Yos Soedarso.

\section{Alat yang Digunakan Dalam Penelitian}

Adapun alat yang digunakan dalam penelitian ini adalah:

1. Meteran

2. Alat tulis

3. Kamera

4. Laptop

\section{Pelaksanaan Survey}

Pelaksanaan survey geometrik jalan dilakukan selama 1 hari pada tanggal 3 Juli 2016 dan survey hambatan samping dilakukan dari tanggal 4-6 Juli 2016.

\section{Tahapan Penelitian}

1. Identifikasi permasalahan

2. Persiapan alat dan tenaga surveyor untuk survey lapangan

3. Pengumpulan data primer dan data sekunder

4. Menghitung kapasitas ruas jalan pada kondisis eksisting

5. Menghitung kapasitas ruas jalan dengan melebarkan ruas jalan ke arah centre line sebesar 0,5 meter, 1 meter dan 1,5 meter.

6. Menganalisis perubahan kapasitas yang terjadi.

7. Menarik sebuah kesimpulan

8. Selesai

\section{Bagan Alir Penelitian}

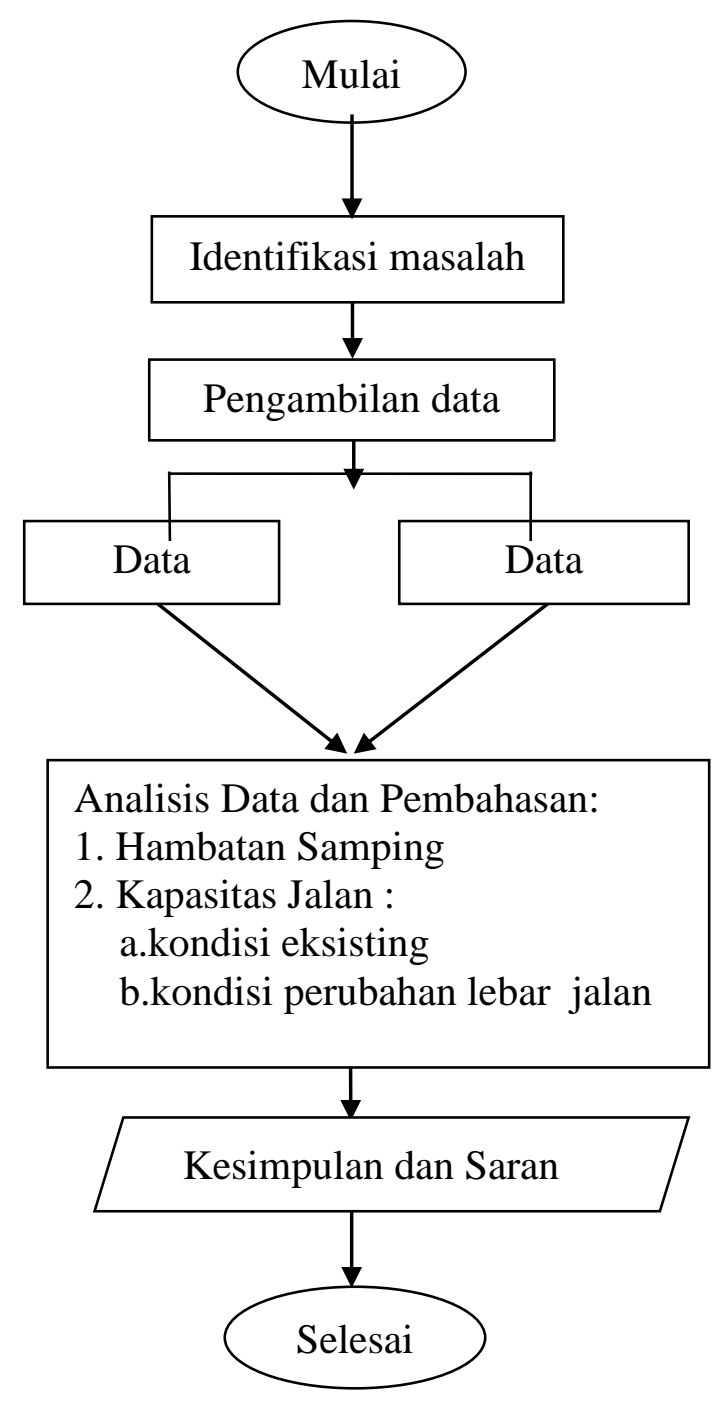

Gambar 1. Diagram Alir Penelitian 


\section{HASIL DAN PEMBAHASAN}

\section{Data Geometrik Jalan}

Lebar masing-masing ruas jalan A dan B serta lebar median dapat dilihat pada Tabel berikut ini.

Tabel 14. Lebar ruas jalan dan median

\begin{tabular}{lccc}
\hline \multirow{2}{*}{ Nama Jalan } & \multicolumn{2}{c}{$\begin{array}{c}\text { Lebar Ruas Jalan } \\
\text { (meter) }\end{array}$} & $\begin{array}{c}\text { Lebar } \\
\text { Median }(\mathbf{m})\end{array}$ \\
\cline { 2 - 3 } & $\mathbf{A}$ & $\mathbf{B}$ & \\
\hline Diponegoro & 7,80 & 6,82 & 5,62 \\
RTA.Milono & 7,50 & 9,73 & 6,07 \\
Imam Bonjol & 9,45 & 9,08 & 5,39 \\
Yos Soedarso & 7,98 & 7,82 & 5,63 \\
G. Obos & 7,28 & 7,90 & 6,08 \\
\hline
\end{tabular}

Keterangan :

1. Jalan Diponegoro:

Arah A menuju bundaran sinyal lalu lintas, arah B arah sebaliknya.

2. Jalan RTA.Milono:

Arah A menuju bundaran sinyal lalu lintas, arah B arah sebaliknya.

3. Jalan Imam Bonjol:

Arah A menuju bundaran sinyal lalu lintas, arah B menuju bundaran besar.

4. Jalan Yos Soedarso:

Arah A menuju bundaran besar, arah B arah sebaliknya.

5. Jalan G.Obos:

Arah A menuju bundaran sinyal lalu lintas, arah B arah sebaliknya.

\section{Lebar bahu dan jarak kerb-penghalang}

Lebar bahu dan jarak kerb ke penghalang mempengaruhi besar kecilnya kapasitas suatu ruas jalan perkotaan. Data lebar trotoar untuk jalan lainnya dapat dilihat pada tabel berikut ini.

Tabel 15. Lebar trotoar dan jarak ke penghalang

\begin{tabular}{lcccc}
\hline \multirow{2}{*}{ Nama Jalan } & \multicolumn{2}{c}{$\begin{array}{c}\text { Lebar Trotoar } \\
\text { (meter) }\end{array}$} & \multicolumn{2}{c}{$\begin{array}{c}\text { Jarak ke } \\
\text { Penghalang (meter) }\end{array}$} \\
\cline { 2 - 5 } & $\mathbf{A}$ & $\mathbf{B}$ & $\mathbf{A}$ & $\mathbf{B}$ \\
\hline Diponegoro & 6,18 & 4,32 & 2,95 & 3,42 \\
RTA.Milono & 4,34 & - & 3,02 & - \\
Imam Bonjol & 3,30 & 3,06 & 2,37 & 2,63 \\
Yos Suedarso & 1,13 & 1,09 & 0,34 & 0,35 \\
G. Obos & 3,10 & 1,57 & 2,53 & 0,15 \\
\hline
\end{tabular}

Ruas A Jalan RTA. Milono pada sisi jalannya terdapat trotoar, sedang pada ruas B memiliki bahu jalan dengan lebar 0,99 meter dan jarak ke penghalang 0,42 meter.

\section{Kelas Hambatan Samping}

Dari hasil rekap data survey hambatan samping dapat diketahui kelas hambatan samping masing-masing ruas jalan adalah sebagai berikut :
Tabel 16. Data hambatan samping

\begin{tabular}{ccc}
\hline Waktu & $\begin{array}{c}\text { Faktor } \\
\text { Terbobot }\end{array}$ & $\begin{array}{c}\text { Kelas Hambatan } \\
\text { Samping }\end{array}$ \\
\hline Diponegoro & 314 & Sedang (M) \\
RTA.Milono & 302 & Sedang (M) \\
Imam Bonjol & 103 & Rendah (L) \\
Yos Suedarso & 105 & Rendah (L) \\
G.Obos & 136 & Rendah (L) \\
\hline
\end{tabular}

\section{Menghitung Kecepatan Arus Bebas (FV)}

1. Kecepatan arus bebas dasar $\left(F_{0}\right)$

Untuk jalan tipe 4/2 D, kecepatan arus bebas dasar untuk kendaraan ringan adalah $\mathrm{FV}_{\mathrm{o}}=57 \mathrm{~km} / \mathrm{jam}$.

\section{Faktor kecepatan arus bebas untuk lebar per lajur}

Arah : A

Tabel 17. Faktor lebar jalan per lajur arah A

\begin{tabular}{ccc}
\hline Jalan & Lebar lajur & $\begin{array}{c}\mathbf{F V}_{\mathbf{W}} \\
(\mathbf{s m p / j a m})\end{array}$ \\
\hline Diponegoro & 3,9 & 3,2 \\
RTA.Milono & 3,75 & 2,0 \\
Imam Bonjol & 3,15 & $-2,8$ \\
Yos Suedarso & 3,99 & 3,92 \\
G.Obos & 3,64 & 1,2 \\
\hline
\end{tabular}

Arah : B

Tabel 18. Faktor lebar jalan per lajur arah B

\begin{tabular}{ccc}
\hline Jalan & Lebar lajur & $\begin{array}{c}\mathbf{F V}_{\mathbf{W}} \\
(\mathbf{s m p} / \mathbf{j a m})\end{array}$ \\
\hline Diponegoro & 3,41 & $-0,72$ \\
RTA.Milono & 3,24 & $-2,08$ \\
Imam Bonjol & 3,03 & $-3,76$ \\
Yos Suedarso & 3,91 & 3,28 \\
G.Obos & 3,95 & 3,6 \\
\hline
\end{tabular}

\section{Faktor hambatan samping dan lebar} bahu jalan dan Kerb-penghalang

\section{Arah : A}

Tabel 19. Faktor hambatan samping, kerbpenghalang

\begin{tabular}{lccc}
\hline \multicolumn{1}{c}{ Jalan } & Kelas RSU & Jarak kerb & FV $_{\mathbf{S F}}$ \\
\hline Diponegoro & $\mathrm{M}$ & 2,95 & 0,99 \\
RTA.Milono & $\mathrm{M}$ & 3,03 & 0,99 \\
Imam Bonjol & $\mathrm{L}$ & 2,37 & 1,00 \\
Yos Suedarso & $\mathrm{L}$ & 0,34 & 0,97 \\
G.Obos & $\mathrm{L}$ & 2,53 & 1 \\
\hline
\end{tabular}

\section{Arah : B}

Tabel 20. Faktor hambatan samping, kerbpenghalang

\begin{tabular}{cccc}
\hline Jalan & Kelas RSU & $\begin{array}{c}\text { Jarak kerb- } \\
\text { penghalang }\end{array}$ & $\mathbf{F V}_{\text {SF }}$ \\
\hline Diponegoro & M & 3,42 & 0,99 \\
RTA.Milono & M & $* 0,42$ & 0,94 \\
Imam Bonjol & $\mathrm{L}$ & 2,63 & 1,00 \\
Yos Suedarso & $\mathrm{L}$ & 0,35 & 0,97 \\
G.Obos & $\mathrm{L}$ & 0,15 & 0,97 \\
\hline
\end{tabular}

Keterangan : (*) untuk bahu jalan 


\section{Faktor ukuran kota}

Kota Palangka Raya berpenduduk 244.500 jiwa, termasuk kriteria kota kecil dengan $\mathrm{FV}_{\mathrm{CS}}=0,93$

\section{Kecepatan Arus Bebas $\left(F_{V}\right)$}

Kecepatan arus bebas pada masingmasing ruas jalan Diponegoro, RTA. Milono, Imam Bonjol, Yos Soedarso dan G Obos untuk arah $\mathrm{A}$ dan arah $\mathrm{B}$ dapat dilihat pada tabel berikut ini yang menunjukan kondisi kecepatan arus lalu lintas masih baik dan berjalan dengan lancar.

Tabel 21. Kecepatan arus bebas

\begin{tabular}{ccc}
\hline \multirow{2}{*}{ Jalan } & \multicolumn{2}{c}{ Kecepatan Arus Bebas (FV) } \\
\cline { 2 - 3 } & A & B \\
\hline Diponegoro & 55,43 & 51,82 \\
RTA.Milono & 54,32 & 48,01 \\
Imam Bonjol & 50,41 & 49,51 \\
Yos Suedarso & 54,96 & 54,38 \\
G.Obos & 54,05 & 54,67 \\
\hline
\end{tabular}

\section{Kapasitas $(C)$}

\section{Kapasitas Dasar $\left(\mathbf{C}_{\mathbf{o}}\right)$}

Kapasitas dasar $\left(\mathrm{C}_{\mathrm{o}}\right)$ jalan perkotaan dipengaruhi oleh tipe jalan serta jumlah lajur pada ruas yang ditinjau. Seperti pada tabel berikut ini :

\begin{tabular}{lcc}
\multicolumn{2}{c}{ Tabel 22.} & Kapasitas dasar ruas A \\
\hline \multicolumn{1}{c}{ Jalan } & Jumlah Lajur & $\mathbf{C}_{\mathbf{0}}$ (smp/jam) \\
\hline Diponegoro & 2 & 3300 \\
RTA.Milono & 2 & 3300 \\
Imam Bonjol & 3 & 4950 \\
Yos Suedarso & 2 & 3300 \\
G.Obos & 2 & 3300 \\
\hline
\end{tabular}

Tabel 23. Kapasitas dasar ruas B

\begin{tabular}{lcc}
\hline \multicolumn{1}{c}{ Jalan } & Jumlah Lajur & $\mathbf{C}_{\mathbf{o}}(\mathbf{s m p} / \mathbf{j a m})$ \\
\hline Diponegoro & 2 & 3300 \\
RTA.Milono & 3 & 4950 \\
Imam Bonjol & 3 & 4950 \\
Yos Suedarso & 2 & 3300 \\
G.Obos & 2 & 3300 \\
\hline
\end{tabular}

\section{Faktor pengaruh lebar jalan $\left(F_{W}\right)$}

Lebar lajur minimum pada (tabel faktor pengaruh lebar jalan) adalah 3 meter. Maka untuk ruas jalan yang mempunyai lebar (L) antara $6 \leq \mathrm{L}<9$ meter, dibuat menjadi 2 lajur.

Arah : A

Tabel 24. Faktor $\mathrm{F}_{\mathrm{W}}$ ruas jalan $\mathrm{A}$

\begin{tabular}{cccc}
\hline Jalan & $\begin{array}{c}\text { Tipe } \\
\text { jalan }\end{array}$ & $\begin{array}{c}\text { Lebar per } \\
\text { lajur }\end{array}$ & $\mathbf{F}_{\mathbf{W}}$ \\
\hline Diponegoro & $2 / 1$ & 3,9 & 1,064 \\
RTA.Milono & $2 / 1$ & 3,75 & 1,040 \\
Imam Bonjol & $3 / 1$ & 3,15 & 0,944 \\
Yos Suedarso & $2 / 1$ & 3,99 & 1,078 \\
G. Obos & $2 / 1$ & 3,64 & 1,022 \\
\hline
\end{tabular}

Arah : B

Tabel 25. Faktor $\mathrm{F}_{\mathrm{W}}$ ruas jalan $\mathrm{B}$

\begin{tabular}{|c|c|c|c|}
\hline Jalan & $\begin{array}{c}\text { Tipe } \\
\text { Jln }\end{array}$ & $\begin{array}{l}\text { Lebar } \\
\text { Lajur }\end{array}$ & $\mathbf{F}_{\mathrm{CW}}$ \\
\hline Diponegoro & $2 / / 1$ & 3,41 & 0,986 \\
\hline RTA.Milono & $3 / 1$ & 3,24 & 0,958 \\
\hline Imam Bonjol & $3 / 1$ & 3,03 & 0,925 \\
\hline Yos Suedarso & $2 / 1$ & 3,91 & 1,066 \\
\hline G. Obos & $2 / 1$ & 3,95 & 1,072 \\
\hline
\end{tabular}

\section{Faktor Pembagi Arah $\left(F_{S P}\right)$}

Untuk suatu tipe jalan terbagi (dengan median) atau jalan satu arah, diambil faktor $\mathrm{F}_{\mathrm{SP}}=1$

\section{Faktor Hambatan Samping ( $\left.F_{\text {RSU }}\right)$}

\section{Ruas A :}

Tabel 26. Faktor hambatan samping ruas jalan A

\begin{tabular}{ccc}
\hline Waktu & $\begin{array}{c}\text { Jarak } \\
\text { Penghalang }\end{array}$ & $\mathbf{F}_{\mathbf{R S U}}$ \\
\hline Diponegoro & 2,95 & 0,98 \\
RTA.Milono & 3,02 & 0,98 \\
Imam Bonjol & 2,37 & 1,00 \\
Yos Suedarso & 0,344 & 1,00 \\
G. Obos & 2,53 & 1,00 \\
\hline
\end{tabular}

\section{Ruas B:}

Tabel 27. Faktor hambatan samping ruas jalan $\mathrm{B}$

\begin{tabular}{ccc}
\hline Waktu & $\begin{array}{c}\text { Jarak } \\
\text { penghalang }\end{array}$ & $\mathbf{F}_{\mathbf{R S U}}$ \\
\hline Diponegoro & 3,42 & 0,98 \\
RTA.Milono & 0,42 & 0,91 \\
Imam Bonjol & 2,63 & 1,00 \\
Yos Suedarso & 0,354 & 0,94 \\
G. Obos & 0,147 & 0,94 \\
\hline
\end{tabular}

\section{Faktor Ukuran Kota $\left(F_{C S}\right)$}

Kota Palangka Raya berpenduduk antara 0,1-0,5 juta jiwa, yang berarti mempunyai nilai faktor ukuran kota sebesar $\mathrm{F}_{\mathrm{CS}}=0,9$. Dari hasil analisa data didapatkan nilai kapasitas masing-masing ruas jalan untuk kondisi lebar eksisting dan penambahan lebar $0,5 \mathrm{~m}, 1,0 \mathrm{~m}$ dan $1,5 \mathrm{~m}$ seperti yang di tabelkan pada tabel berikut ini

\section{Kondisi Eksisting :}

Tabel 28. Kapasitas jalan kondisi eksisting

\begin{tabular}{ccc}
\hline \multirow{2}{*}{ Jalan } & \multicolumn{2}{c}{ Kapasitas } \\
\cline { 2 - 3 } & Ruas A & Ruas B \\
\hline Diponegoro & 3096,88 & 2869,85 \\
RTA.Milono & 3027,02 & 3883,78 \\
Imam Bonjol & 4205,52 & 4120,88 \\
Yos Suedarso & 3201,66 & 2976,06 \\
G. Obos & 3035,34 & 2992,81 \\
\hline
\end{tabular}




\section{Kondisi Pelebaran Jalan :}

1. Faktor lebar jalan (FCw) :

Ruas A :

Tabel 29. Perubahan faktor FCw ruas jalan A

\begin{tabular}{cccc}
\hline \multirow{2}{*}{ Jalan } & \multicolumn{3}{c}{ Nilai FCw } \\
\cline { 2 - 4 } & $\begin{array}{c}\mathbf{L}=\mathbf{0 , 5} \\
\text { (meter) }\end{array}$ & $\begin{array}{c}\text { L=1,0 } \\
\text { (meter) }\end{array}$ & $\begin{array}{c}\mathbf{L}=\mathbf{1 , 5} \\
\text { (meter) }\end{array}$ \\
\hline Diponegoro & 1,104 & 1,144 & 0,936 \\
RTA.Milono & 1,080 & 1,120 & 0,920 \\
Imam Bonjol & 0,971 & 0,997 & 1,024 \\
Yos Suedarso & 1,118 & 1,158 & 0,946 \\
G. Obos & 1,062 & 1,102 & 1,142 \\
\hline
\end{tabular}

\section{Ruas B :}

Tabel 30. Perubahan faktor FCw ruas jalan B

\begin{tabular}{cccc}
\hline \multirow{2}{*}{ Jalan } & \multicolumn{3}{c}{ Nilai FCw } \\
\cline { 2 - 4 } & $\begin{array}{c}\mathbf{L}=\mathbf{0 , 5} \\
\text { (meter) }\end{array}$ & $\begin{array}{c}\text { L=1,0 } \\
\text { (meter) }\end{array}$ & $\begin{array}{c}\mathbf{L}=\mathbf{1 , 5} \\
\text { (meter) }\end{array}$ \\
\hline Diponegoro & 1,026 & 1,076 & 1,106 \\
RTA.Milono & 0,986 & 1,013 & 1,038 \\
Imam Bonjol & 0,950 & 0,978 & 1,005 \\
Yos Suedarso & 1,106 & 1,146 & 0,938 \\
G. Obos & 1,112 & 1,152 & 0,941 \\
\hline
\end{tabular}

\section{Perubahan nilai kapasitas (C) jalan}

Ruas A :

Tabel 31. Perubahan Kapasitas ruas jalan A

\begin{tabular}{cccc}
\hline \multirow{2}{*}{ Jalan } & \multicolumn{3}{c}{$\begin{array}{c}\text { Nilai Kapasitas (C) (smp/jalan) } \\
\text { Dengan penambahan lebar jalan }\end{array}$} \\
\cline { 2 - 4 } & $\begin{array}{c}\mathbf{L}=\mathbf{0 , 5} \\
\text { (meter) }\end{array}$ & $\begin{array}{c}\mathbf{L}=\mathbf{1 , 0} \\
(\mathbf{m e t e r})\end{array}$ & $\begin{array}{c}\mathbf{L}=\mathbf{1 , 5} \\
\text { (meter) }\end{array}$ \\
\hline Diponegoro & 3213,30 & 3329,73 & 4086,48 \\
RTA.Milono & 3143,45 & 3259,87 & 4016,63 \\
Imam Bonjol & 4325,81 & 4441,64 & 4561,92 \\
Yos Suedarso & 3320,46 & 3439,26 & 4214,43 \\
G. Obos & 3154,14 & 3272,94 & 3391,74 \\
\hline
\end{tabular}

\section{Ruas B :}

Tabel 32. Perubahan kapasitas ruas jalan B

\begin{tabular}{cccc}
\hline \multirow{2}{*}{ Jalan } & \multicolumn{3}{c}{ Nilai Kapasitas (smp/jalan) } \\
& Dengan penambahan lebar jalan (L) \\
\cline { 2 - 4 } & $\begin{array}{c}\text { L=0,5 } \\
\text { (meter) }\end{array}$ & $\begin{array}{c}\text { L=1,0 } \\
\text { (meter) }\end{array}$ & $\begin{array}{c}\text { L = 1,5 } \\
\text { (meter) }\end{array}$ \\
\hline Diponegoro & 2986,28 & 3131,81 & 3217,96 \\
RTA.Milono & 4304,78 & 4422,66 & 4531,80 \\
Imam Bonjol & 4234,03 & 4356,99 & 4477,28 \\
Yos Suedarso & 3283,63 & 3403,62 & 4178,79 \\
G. Obos & 3302,64 & 3421,44 & 4192,16 \\
\hline
\end{tabular}

Pelebaran jalan-jalan primer di Kota Palangka Raya seperti yang ditunjukan pada tabel 31 dan tabel 32 memberikan pengaruh positip, yaitu meningkatkan kapasitas jalan yang berarti melancarkan gerakan arus lalu lintas pada ruas jalan tersebut. Seperti kita ketahui, adanya usaha peningkatan kapasitas jalan berarti terjadi peningkatan volume lalu lintas pada ruas jalan tersebut, hal ini memberikan dampak negatif terhadap lingkungan, yaitu polusi udara dan suara.
Salah satu pencemaran udara yang terjadi diakibatkan oleh gas buang kendaraan. Alternatif yang dapat dilakukan untuk mengurangi dampak polusi tersebut adalah dengan menanam atau memanfaatkan tanaman/pohon di sekitar lingkungan tersebut, seperti menanam Pohon Tanjung (Mimusops elengi), karena mampu menyerap gas buangan kendaraan sebesar 35,94 $\mathrm{mg} / \mathrm{m} 2$. Jenis pohon dominan yang ditanam di median jalan tersebut diantara adalah Pohon Tanjung (Mimusops elengi).

Menurut Martawijaya, dkk (1989) Tanaman Tanjung (Mimusops elengi) dengan klasifikasi sebagai berikut:

$\begin{array}{ll}\text { Divisio } & \text { : Spermatophyta } \\ \text { Sub division } & \text { : Angiospermae } \\ \text { Class } & \text { : Dicotyledoneae } \\ \text { Ordo } & \text { : Ebenales } \\ \text { Family } & \text { : Sapotaceae } \\ \text { Genus } & \text { : Mimusops } \\ \text { Species } & \text { : Mimusops elengi }\end{array}$

Manfaat Pohon Tanjung diantaranya dapat berfungsi sebagai penyerap pencemaran udara khususnya $\mathrm{Pb}$. Tumbuhan mempunyai kemampuan menjerap dan mengakumulasi zat pencemar. Tumbuhan melalui daunnya dapat menangkap partikel timbal yang diemisikan kandaraan bermotor (Djuangsih dalam Siringoringo 2000).

Menurut Koeppe dan Miller dalam Siringoringo, kemampuan tanaman dalam menjerap timbal sangat dipengaruhi keadaan permukaan daun tanaman. Daun yang mempunyai bulu (pubescent) atau daun yang permukaannya kesat (berkerut) mempunyai kemampuan yang lebih tinggi dalam menyerap timbal, daripada daun yang mempunyai permukaan lebih licin dan rata. Hal yang sama juga dinyatakan oleh Strakman dalam Siringoringo (1969) bahwa kemampuan daun tanaman menyerap suatu polutan dipengaruhi oleh karakteristik morfologi daun, seperti ukuran dan bentuk daun, adanya rambut pada permukaan daun dan juga tekstur daun.

Bukti/ efek dari penyerapan polutan oleh paparan $\mathrm{CO}, \mathrm{NO}_{\mathrm{x}}, \mathrm{SO}_{\mathrm{x}}$ dan timbal pada tanaman tanjung adalah mudah dijumpai pada daun. Contoh efek akut adalah klorosis 
dan nekrosis pada permukaan daun yang dapat menyebabkan jaringan daun menjadi rusak dan mati sehingga disimpulkan bahwa pemaparan emisi kendaraan memberikan efek negatif. Ditandai dengan jumlah daun yang rusak pada tanaman yang diberi pemaparan polutan lebih banyak daripada daun control (Hendrasarie 2007).

Manfaat lainnya seperti penyerap dan penapis bau, peredam kebisingan, mengurangi bahaya hujan asam akibat polusi udara, penyerap karbon monoksida dan karbon dioksida serta menghasilkan oksigen, penahan angin dan lain-lain. Hasil survey pada jalan-jalan primer yang ada di Kota Palangka Raya menunjukkan bahwa pohon tanjung merupakan tanaman dominan sebagai tanaman hijau. Hal ini disebabkan karena pohon tanjung termasuk salah satu jenis tanaman pohon yang dapat menyerap karbon monoksida dengan baik, seperti yang ditunjukan tabel berikut ini:

Tabel 33. Kemampuan Penyerapan Tanaman Terhadap Karbon Monoksida

\begin{tabular}{llll}
\hline No & $\begin{array}{c}\text { Nama } \\
\text { Pohon }\end{array}$ & \multicolumn{1}{c}{ Nama Latin } & $\begin{array}{c}\text { Serapan } \\
(\mathbf{m g} / \mathbf{m} 2)\end{array}$ \\
\hline 1 & Damar & Agatis alba & 54,90 \\
2 & Mahoni & Swetenia mahagoni & 41,80 \\
3 & Jamuju & $\begin{array}{l}\text { Sitenia mahagoni } \\
\text { Podocarpus }\end{array}$ & 45,52 \\
4 & Pala & inmbricatus & 49,25 \\
& & Miristyca fragrans & 57,24 \\
5 & Asem Londo & Casia ciamea & 50,50 \\
6 & Johar & Barintonia asiatica & 33,31 \\
7 & Keben & Mimusops elengi & 35,94 \\
8 & Tanjung & & \\
\hline
\end{tabular}

Pelebaran ruas jalan yang dilakukan berarti mempersempit lebar median jalan yang sekaligus sebagai area tanaman/pohon tersebut sebesar $0,5 \mathrm{~m}, 1,0 \mathrm{~m}$ dan $1,5 \mathrm{~m}$. Hal ini tentu saja memberikan dampak negatif pada lingkungan, yaitu berkurangnya tanaman yang mampu menyerap karbon monoksida hasil pembakaran mesin kendaraan tersebut dengan kemampuan serap sebesar 35,94 mg, 71,88 mg dan 107,82 mg untuk setiap 1 meter panjang ruas jalan.

\section{KESIMPULAN}

Berdasarkan penelitian yang telah dilakukan, maka dapat dibuat kesimpulan berikut.

1. Pelebaran ruas jalan A dan B sebesar $0,5 \mathrm{~m}, 1,0 \mathrm{~m}$ dan $1,5 \mathrm{~m}$ ke arah as jalan memberikan pengaruh positif yaitu meningkatnya kapasitas ruas jalan.

2. Kapasitas jalan di beberapa jalan di Palangka Raya adalah sebagai berikut.

(a) Kapasitas Jalan Diponegoro ruas A meningkat sebesar 3,73\%, 7,52\% dan $31,95 \%$, ruas $\mathrm{B} 4,06 \%, 9,13 \%$ dan $12,13 \%$.

(b) Kapasitas jalan RTA.Milono ruas A meningkat sebesar 3,85\%, 7,69\% dan $32,69 \%$, ruas $\mathrm{B} 10,84 \%$, $13,88 \%$ dan $16,69 \%$.

(c) Kapasitas jalan Imam Bonjol ruas A meningkat sebesar 2,86\%, 5,61\% dan $8,47 \%$, ruas $\mathrm{B} 2,74 \%, 5,73 \%$ dan $8,65 \%$.

(d) Kapasitas jalan Yos Soedarso ruas A meningkat sebesar 3,71\%, 7,42\% dan $31,63 \%$, ruas $\mathrm{B} 10,33 \%$, $14,37 \%$ dan $40,41 \%$.

(e) Kapasitas jalan G. Obos ruas A meningkat sebesar 3,91\%, 7,83\% dan $11,74 \%$, ruas $\mathrm{B} 10,35 \%$, $14,32 \%$ dan $40,07 \%$.

3. Pelebaran ruas jalan mengakibatkan menyempitnya lebar median jalan yang juga sebagai media tanaman pohon yang bermanfaat untuk menyerap gas buang kendaraan sampai dengan $35,94 \mathrm{mg} / \mathrm{m} 2$. Tentu saja hal ini memberikan dampak negatif terhadap lingkungan, yaitu berkurangnya tanaman yang mampu menyerap karbon monoksida hasil pembakaran mesin kendaraan tersebut dengan kemampuan serap sebesar 35,94 $\mathrm{mg}, 71,88 \mathrm{mg}$ dan $107,82 \mathrm{mg}$ untuk setiap 1 meter panjang ruas jalan. 


\section{DAFTAR PUSTAKA}

Alik A. A., 2005, Rekayasa Lalu Lintas, Penerbit Universitas Muhammadiyah Malang, Malang.

BPS, 1999, Kotamadya Palangka Raya Dalam Angka, Badan Pusat Statistik Palangka Raya.

Brutton, M. J., 1985, Intruduction to Transportation Planning, Hutchinson and Co Ltd, London.

Djuangsih N., Hendarto, Soemarwoto, O., 1988, Air Pollution by Lead and Health in Bandung City.
Departemen Kehutanan RI, 2009, Hutan Kota untuk Pengelolaan dan Peningkatan Kualitas Lingkungan Hidup. $\quad$ http://www.dephut.go.id. Diakses tanggal 20 Agustus 2016.

Hobbs, F. D., 1995, Perencanaan dan Teknik Lalu Lintas, Penerbit Gajah Mada University Press, Yogyakarta.

Siringoringo, H., 2000, Kemampuan Beberapa Jenis Tanaman Hutan Kota dalam Menjerap Partikulat Timbal, Bul. Pen. Hutan. 